\title{
Synthesis, Characterization and Biological Activity of Schiff Bases Based on Chitosan and Acetophenone Derivatives
}

\author{
Olivia Hanaa Raoufa, Samy Selimb,c, Hussein Mohamed d,*,Omayma Fawazy Abdel-Gawada, Ali \\ Mahmoud Elzanatya, Sayed Abdel-Kader Ahmed
}

\author{
a Department of Chemistry, Faculty of Science, Beni-Suef University, Beni-Suef, Egypt \\ b Department of Clinical Laboratory Sciences, College of Applied Medical Sciences, Jouf University, Sakaka P.O. 2014, \\ Saudi Arabia \\ c Botany Department, Faculty of Science, Suez Canal University, Ismailia P.O. 41522, Egypt \\ $\mathrm{d}$ Research institute of Medicinal and Aromatic Plants (RIMAP), Beni-Suef University, Egypt
}

\section{A R T I C L E I N F O}

Received: 11 July 2019

Revised: 19 July 2019

Accepted: 07 September 2019

Available online: 12 September 2019

\section{K E Y W O R D S}

\section{Chitosan}

Schiff base

Antimicrobial

Antioxidant

Anti-protozoal

\section{A B S T R A C T}

Modification of chitosan any Schiff base reaction with acetophenone derivatives was done. Fourier transformer infrared analysis (FT-IR), scanning electron microscope (SEM), and X-ray diffraction (XRD) were used as the appropriate characterize the Schiff base derivatives. Thermal behavior of the prepared materials was also studied. Various biological activities were examined for the prepared materials antimicrobial activity including antibacterial (studied against Streptococcus sp. Bacillus subtilis and Sarcina lutea as an example for gram-positive bacteria and Pseudomonas aeruginosa and Escherichia coli as an example for Gram-negative bacteria), anti-fungal (against Candida albicans) and anti-protozoal (against Trypanosoma cruzi and Leishmania donovaniwas). Antioxidant activity of chitosan and its Schiff base derivatives was detected using the FRAP and DPPH techniques. Colon carcinoma (Colo 205), hepatocellular carcinoma (Hep G2), urinary bladder carcinoma (T24P) and embryonic kidney adenocarcinoma (293) used to examine the anticancer activity of chitosan and its modified derivatives. The new chitosan Schiff base derivatives showed superior anti-bacterial, antifungal, anti-protozoal and antioxidant activity than parent chitosan. But in case of anticancer test of HebG2 and T24P chitosan was more effective than the modified derivatives.

*Corresponding author's E-mail address: h_gendy_2010@yahoo.com 


\section{GRA P H I CAL ABSTRACT}

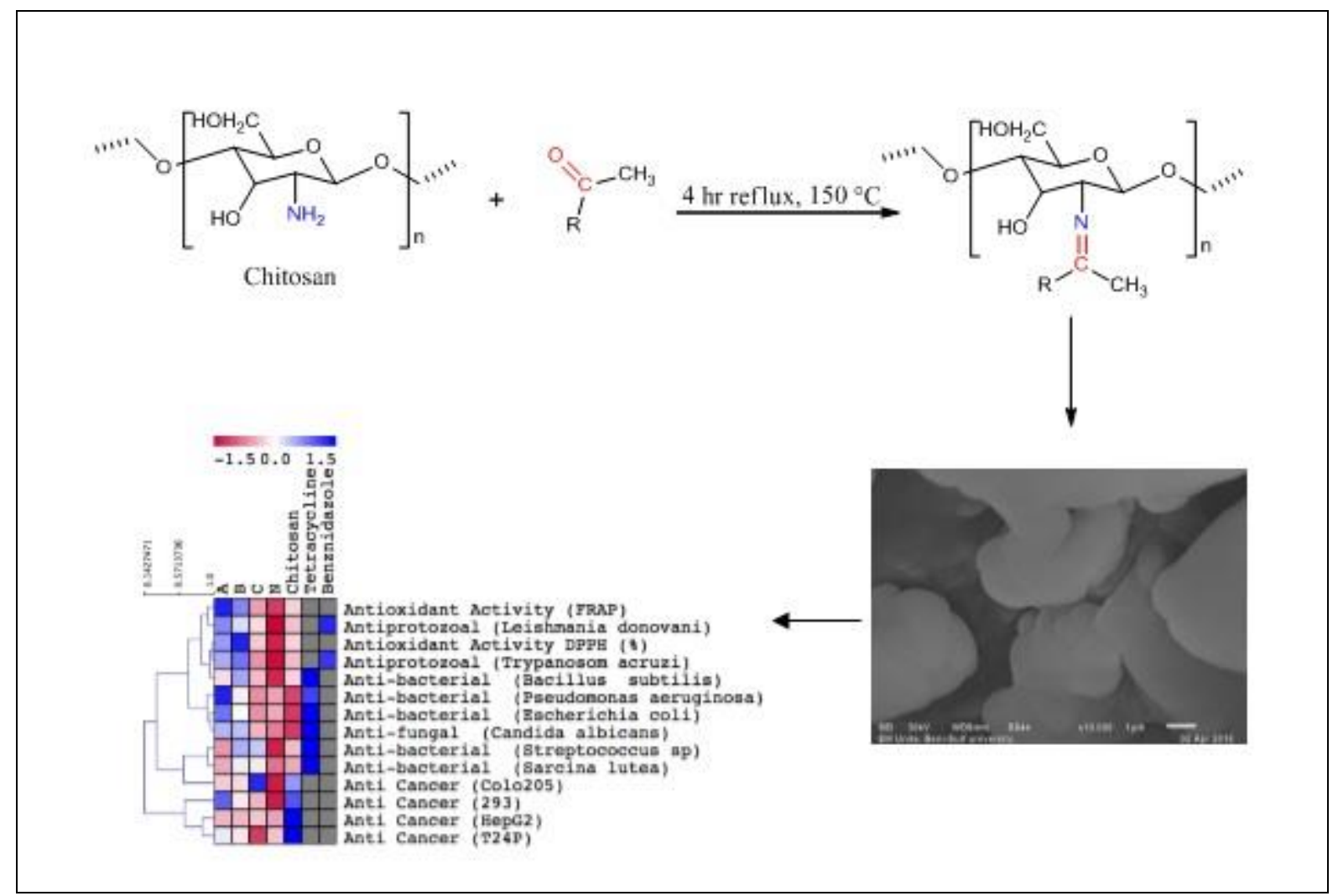

\section{Introduction}

Finding renewable, cheap, and natural materials have extensively increased and biopolymers have over passed these types of material [1-4]. The most elegant biopolymer is chitin that is found in the cell walls of yeast, and fungi exists in lower plant and animal kingdoms but presently the main source of chitin is the shells of marine living organisms such as shells of crabs and shrimps. It is considered to be the second abundant biopolymer in nature while cellulose is considered to be the first. After almost 50\% deacetylation and alkaline treatment of the chitin, chitosan is obtained which is the most applicable chitin derivative [5]. Chitosan also can be obtained by many processes such as deproteinization and demineralization [6]. Chitosan has a unique character by being the only pseudo-natural cationic polymer due to $-\mathrm{NH}_{2}$ that found at
C2 of D-glucosamine units and the protonation of amino group leading the solubility of chitosan in the acidic medium [5]. Chitosan is constructed by $N$-acetylated glucosamine units linked by $\beta$-(1-4) glycosidic bonds $[7,8]$. Chitosan has a widefield in biological activities such as antimicrobial, antitumor, and used pharmaceutically as anticoagulant agent [9], also can be useful in several fields such as textiles, environmental protection, water treatment, cosmetics and biotechnology due to its ability to produce bifunctional materials [6-8]. Its structure easy to be modified to several derivatives due to $-\mathrm{OH}$ and $\mathrm{NH}_{2}$ groups found [6] which distinct chitosan from cellulose [5]. The modified chitosan exhibits new properties such as solubility, biological activity [10], biocompatibility, and hydrophilicity [9]. Amino group can be condensed with carbonyl group of aldehydes or ketones 
which known as Schiff base reaction yielding imine group $(-\mathrm{N}=\mathrm{CH}-)$ which is generally known by its antimicrobial activity and antibacterial activity against many of bacteria, fungi and algae organisms, therefore various papers applied the Schiff base mechanism [11] such as synthesis Schiff base chitosan with many aromatic aldehydes (benzaldehyde, $p$-chlorobenzaldehyde, $\quad \mathrm{p}-\mathrm{N}, N$ dimethylaminobenzaldehyde or $p$ methoxybenzaldehyde) showing antibacterial activity [12] and preparation of chitosan Schiff base acetylacetone showed better antibacterial than the original chitosan directly against Staphylococcus aureus and Escherichia coli [9].

Here in, modification of chitosan well achieved by Schiff base reaction with acetophenone derivatives: 4-Aminoacetophenon (Ch-4-aminoacetophenone enone) and 4-bromoacetophenone (Ch-4bromoaceto-phenone). The newly synthesized derivatives are subjected to Fourier transformer infrared analysis (FTIR), scanning electron microscope (SEM) and X-ray diffraction (XRD) as the appropriate characterization techniques. The thermal behavior of new materials was also detected. Antimicrobial activity include anti-bacterial (studied against Gram-positive bacteria such as Streptococcus sp., Bacillus subtilis and for Gram-negative bacteria such as Sarcina lutea and Escherichia coli as well as Pseudomonas aeruginosa), anti-fungal (against Candida albicans), anti-protozoal (against Trypanosoma cruzi and Leishmania donovaniwas). Antioxidant activity of chitosan and its Schiff base derivatives was detected according to FRAP and DPPH methods. Anticancer activity of chitosan and its modified derivatives against colon carcinoma (Colo 205), hepatocellular carcinoma (Hep G2), urinary bladder carcinoma (T24P) and embryonic kidney adenocarcinoma (293) was also examined. The new chitosan Schiff base derivatives showed superior antibacterial, antifungal, anti-protozoal and antioxidant activity than parent chitosan. But in case of anticancer test of Heb G2 and T24P chitosan was more effective than the modified derivatives.

\section{Experimental}

\section{Materials and method}

\section{Materials}

Chitosan with deacetylation degree of 96\% was purchased from Bio Basic Canada INC, 4-aminoacetophenone was purchased from MERCK-Schuchardt and 4bromoacetophenone was purchased from The British Drug Houses LTD.

\section{Experimental method}

Preparation of chitosan acetophenone schiff base

Modified chitosan obtained by adding predetermined amount of chitosan with 25 $\mathrm{mL}$ of Acetophenone derivatives (4Aminoacetophenone and 4Bromoacetophenone) stirring for $4 \mathrm{~h}$ under reflux at $150{ }^{\circ} \mathrm{C}$ (scheme 1). Filtration and washing with water to remove the excess ketone then dry at $60^{\circ} \mathrm{C}$.

\section{Instrumentation}

\section{Infrared spectroscopy}

To confirm the occurrence of the reaction, a Fourier transform infrared (FTIR) spectrometer (VERTEX 70 FT-IR) was used. FT-IR spectra within the wave number ranged from 4000-600 $\mathrm{cm}^{-1}$ were recorded at room temperature in ATR discs. 
Scheme 1. Synthesis of chitosan acetophenone Schiff base derivatives

\section{Scanning electron microscope}

The samples to be characterized were prepared for imaging using SEM (JSM-6510 LA model) which followed a small part of film was placed on carbon tube on a stub and coated after that with thin gold layer. SEM images were taken after that for the samples.

\section{X-ray diffraction}

2020964 PANalytical Empyrean used as a unique technique, which provides crystallite size and phase quantification, along phase identification (diamond or graphite).

\section{Thermogravimetric analysis}

Samples to be thermally analyzed were heated in a platinum pan from 10 to $600^{\circ} \mathrm{C}$ with a heating rate of $10^{\circ} \mathrm{C} / \mathrm{min}^{-1}$ under flow rate of 25 $\mathrm{mL} / \mathrm{min}^{-1}$ of $\mathrm{N}_{2}$ gas. The thermal stability of the prepared samples were followed up using thermogravimetric analyzer (TGA-50H model).

\section{Biological activity assessments}

The commonly utilized diphenylpicrylhydrazyl (DPPH) and ferric reducing antioxidant power (FRAP) assays expressed as \% inhibition of DPPH radical or as $\mu$ mole Trolox equivalent $\mathrm{g}^{-1}$ dry weight, respectively used to

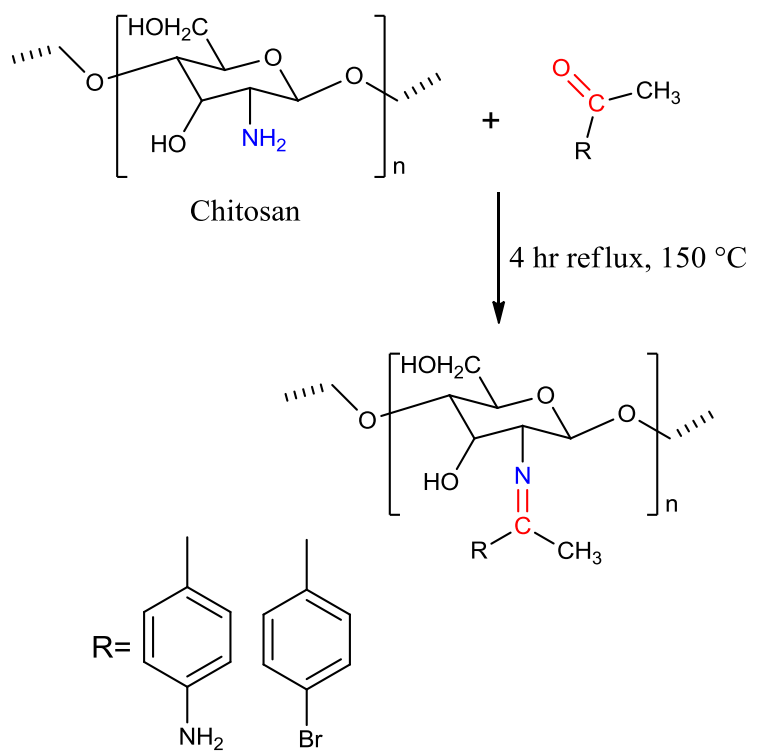

evaluate the antioxidant capacity of the prepared chitosan derivatives. To evaluate the antibacterial activity of the new prepared materials, the diameter of the inhibition zone was determined using disc diffusion technique (7.5 mg/disc) on MHA (Muller Hinton agar) and expressed in mm [17]. In vitro estimation of the antiprotozoal activity of the new prepared materials $(5 \mathrm{mg} / \mathrm{ml})$ toward Trypanosoma cruzi was done according to Brun et al., protocol [17]. The antiprotozoal activity was expressed as reduction percentage in parasite load comparative to the control. Moreover, the anticancer activities of the new prepared materials $(2 \mathrm{mg} / \mathrm{mL})$ were examined against four human cell lines, Colon carcinoma (Colo 205), hepatocellular carcinoma (Hep G2), urinary bladder carcinoma (T24P) and embryonic kidney adenocarcinoma (293). The dead cells \% were used to calculate the viability cells by Solowey method [16] by using Cell Titer-Blue reagent (Promega, Madison, WI, USA).

\section{Results and discussions}

Samples characterization

Infrared spectroscopy

Four strong peaks appeared on the FT-IR spectrum of the chitosan. The first peak 
appeared at $1152 \mathrm{~cm}^{-1}$, the second peak at $1086 \mathrm{~cm}^{-1}$, the third peaks appeared at 1025 $\mathrm{cm}^{-1}$, and the fourth one at $894 \mathrm{~cm}^{-1}$. All of these peaks are characteristic for saccharide ring. The intermolecular hydrogen bonds of polysaccharide, the extension vibration of $\mathrm{NH}_{2}$ and the stretching vibration of $\mathrm{OH}$ groups appear as a very strong broad peak at $3433 \mathrm{~cm}^{-1}$. Primary amine of highly deacylated chitosan has two characteristic peaks at $1651 \mathrm{~cm}^{-1}$ for amide I and 1426 $\mathrm{cm}^{-1}$ for amide II. FT-IR spectrum of chitosan derivatives showed the presence of $\mathrm{O}-\mathrm{H}$ stretching vibration band between 3774$3358 \mathrm{~cm}^{-1}$ as illustrated in Table 1 . The doublet peaks of $-\mathrm{NH}_{2}$ disappeared and two other peaks appeared which indicates the Schiff base reaction between $-\mathrm{NH}_{2}$ of chitosan and $\mathrm{C}=\mathrm{O}$ of acetophenones forming imine group $(\mathrm{N}=\mathrm{C})$ which has characteristic peak around 1690-1648 $\mathrm{cm}^{-1}$ [13]. Also appearance of new characteristic peak for acetophenone derivatives at $1433 \mathrm{~cm}^{-1}$, $1479 \mathrm{~cm}^{-1}, 1380 \mathrm{~cm}^{-1}$ and $1424 \mathrm{~cm}^{-1}$ for Ch4-Aminoacetophenone and Ch-4Bromoacetophenone to confirm the presence of aromatic ring, while the appearance of other new peaks at $3397 \mathrm{~cm}^{-1}$ and $1522-1345 \mathrm{~cm}^{-1}$ for amino group in $\mathrm{Ch}$ 4-Aminoacetophenone shown in Figure 1.

Figure 1. FT-IR analysis (wave number measured in $\mathrm{cm}^{-1}$ ) of (a) Chitosan, (b) Ch4-Bromoacetophenone, Ch-4-Aminoacetophenone

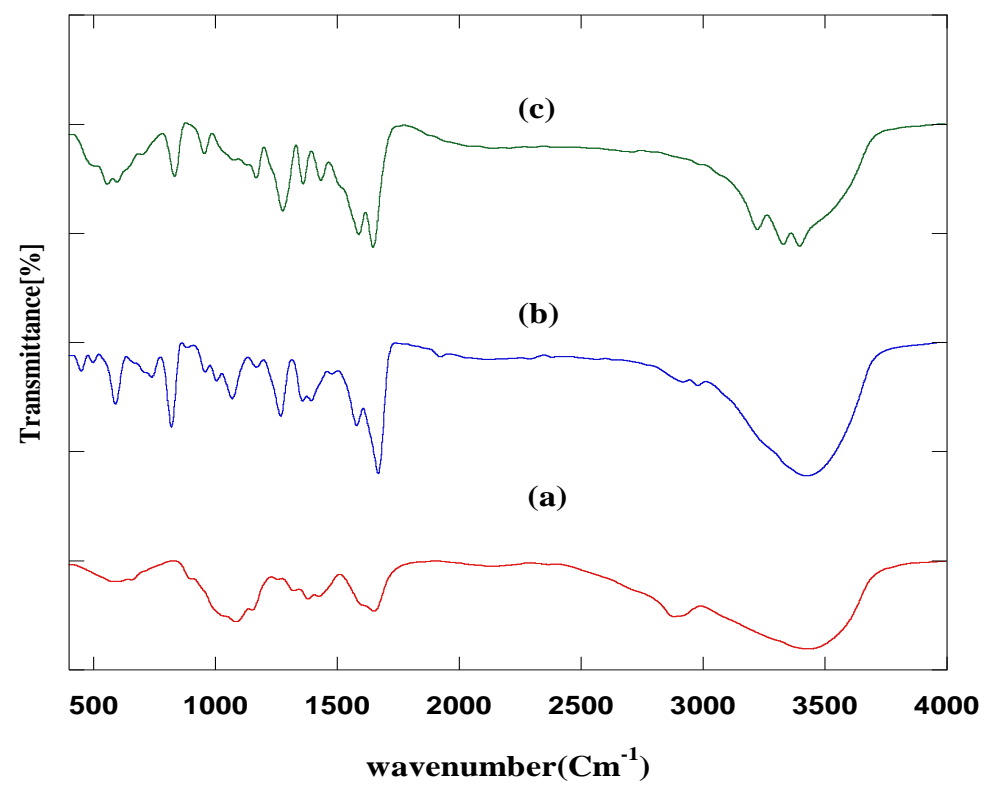

Table 1. FT-IR data of chitosan and its Schiff base derivatives

\begin{tabular}{|c|c|c|c|c|c|c|}
\hline $\begin{array}{l}\text { Types of vibration } \\
\text { Types of } \\
\text { Derivatives }\end{array}$ & $\begin{array}{c}\mathrm{OH} \\
\text { Stretch }\end{array}$ & $\mathrm{NH}_{2}$ & $\begin{array}{l}\mathrm{C}=\mathrm{N} \\
\text { Stretch }\end{array}$ & $\mathrm{C}-\mathrm{N}$ & $\begin{array}{l}\text { C-H } \\
\text { Stretch }\end{array}$ & $\begin{array}{l}\text { C-C } \\
\text { Aromatic } \\
\text { Ring }\end{array}$ \\
\hline Chitosan & 3433 & 3433 & - & 1323 & 2882 & - \\
\hline $\begin{array}{c}\text { h-4- } \\
\text { Bromoacetophenone }\end{array}$ & 3426 & - & 1669 & 1358 & 2918 & 1479 \\
\hline $\begin{array}{c}\text { Ch-4- } \\
\text { Aminoacetophenone }\end{array}$ & 3330 & 3397 & 1648 & 1361 & 2711 & 1443 \\
\hline
\end{tabular}


Thermogravimetric analysis

Figure 2 shows the thermogravimetric analysis of chitosan and its Schiff base derivatives. At $300{ }^{\circ} \mathrm{C}$ we observe that, the residual weight \% (Rwt \%) of unmodified chitosan was about $73 \%$, while the Rwt $\%$ of chitosan derivatives, $\mathrm{Ch}$-4-Bromoacetophenone and $\mathrm{Ch}-4$-Aminoacetophenone were $17.7 \%$ and $27.6 \%$, respectively. At $400{ }^{\circ} \mathrm{C}$ the Rwt \% of unmodified chitosan was $40 . \%$, while the Rwt $\%$ of chitosan derivatives Ch-4Bromoacetophenone and Ch-4Aminoacetophenone were $10.5 \%$ and $20.4 \%$ respectively. At $500{ }^{\circ} \mathrm{C}$ the Rwt $\%$ of unmodified chitosan was $20.8 \%$, while the Rwt $\%$ of Ch-4Bromoacetophenone and Ch-4Aminoacetophenone were $5.3 \%$ and $15.4 \%$ respectively as illustrated in Table 2 . So, the chitosan showed higher thermal stability than the derivatives, almost has thermal stability similar to parent chitosan. Ch-4Bromoacetophenone has the lowest thermal stability. The instability of the Schiff base derivatives compared with parent chitosan was because of the presence of $\mathrm{N}=\mathrm{C}$ group in the prepared Schiffs derivatives. $\mathrm{N}=\mathrm{C}$ group is greatly affected by temperature than chitosan's amino group [14].

\section{$X$-ray diffraction}

Chitosan and its new derivatives spectra are presented in Figure 3. The X-ray diffraction of pure chitosan showed the typical broad peaks at $2 \theta=11^{\circ}$ and $20^{\circ}$ [15], as shown in Figure 3. However, the XRD data for the new derivative Ch-4-Aminoacetophenone showed five peaks at $2 \theta=11^{\circ}, 18^{\circ}, 20^{\circ}, 23^{\circ}$, and $27^{\circ}$, appearance of two new peaks comparing with chitosan.

Figure 2. TGA of $(\mathrm{A})$ Chitosan,

(B) Ch-4-Bromoacetophenone

(C) Ch-4-Aminoacetophenone

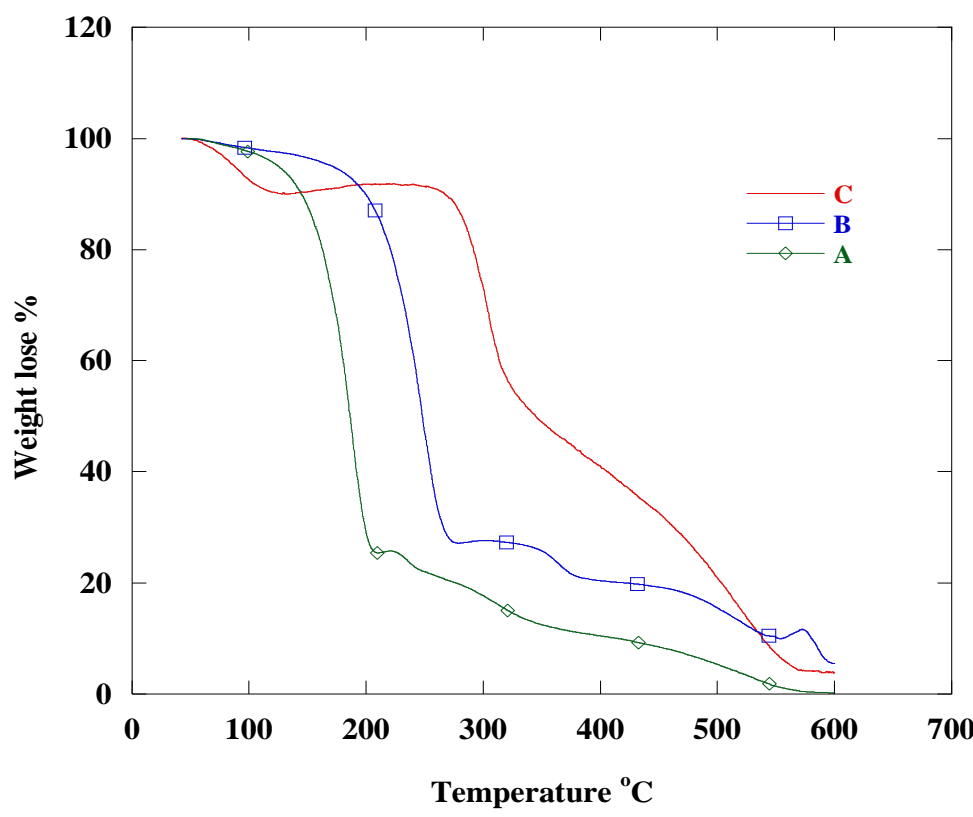

Table 2. TGA data of chitosan and its Schiff base derivatives

\begin{tabular}{cccc} 
Samples & Rwt \% at $300{ }^{\circ} \mathrm{C}$ & Rwt $\%$ at $400{ }^{\circ} \mathrm{C}$ & Rwt $\%$ at $500{ }^{\circ} \mathrm{C}$ \\
Chitosan & 73 & 40.9 & 20.8 \\
Ch-4-Bromoacetophenone & 17.7 & 10.5 & 5.3 \\
Ch-4-Aminoacetophenone & 27.6 & 20.4 & 15.4 \\
\hline
\end{tabular}


For the diffractogram of Ch-4- was found that the surface of the parent Bromoacetophenone showed six peaks at $2 \theta=$ $19^{\circ}, 20^{\circ}, 23^{\circ}, 25^{\circ}, 28^{\circ}$, and $29^{\circ}$ with appearance of five new peaks comparing with the parent chitosan as revealed in Figure 3. The chitosan derivatives showed difference crystalline peaks which introduce additional proof for preparation of Schiff base materials.

\section{Scanning electron microscope}

SEM images of the chitosan and its Schiff base derivatives are represented in Figure 4. It chitosan was fibrous in nature and smooth with some cracks which is extremely changed and became rougher with the appearance of protrusions and peels as compared with the original Chitosan surface. The morphology of the Schiff base derivatives surface was changed as a result of the Schiff base reaction which differs in shape, size and softness from one derivative to another one as shown in Figure 4. The difference of morphology between Chitosan and modified Chitosan confirmed that the Schiff base occurred.

Figure 3. XRD of (a) Chitosan, (b) Ch-4Bromoaceto-phenone, (c) Ch-4-Amino-acetophenone

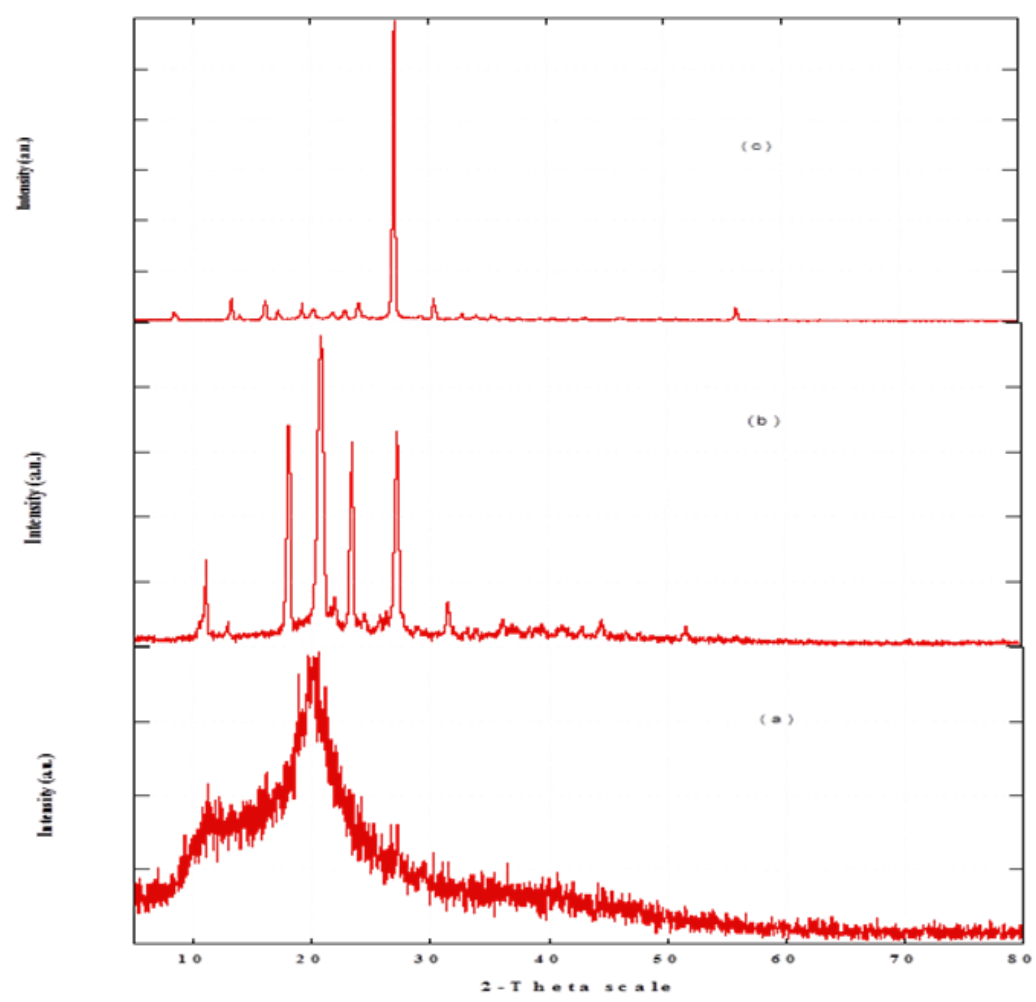

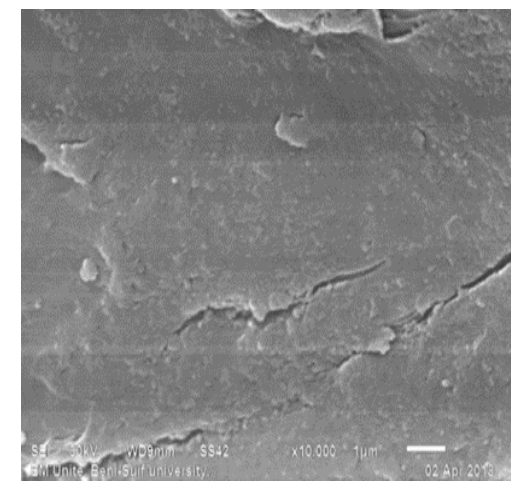

(a)

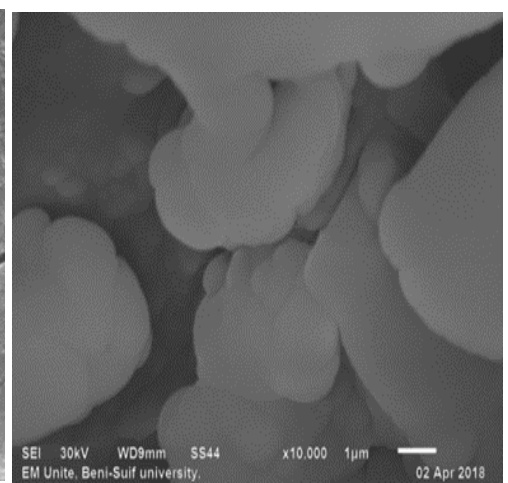

(b)

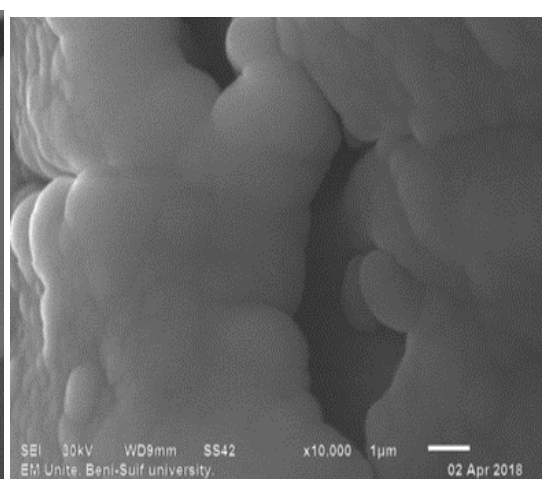

(c)

Figure 4. SEM of (a) Chitosan, (b) Ch-4-Aminoacetophenone, (c) Ch-4-Bromoacetophenone 
Figure 5. Heat map of biological activity of chitosan and its acetophenne Schiff base derivatives Ch-4Aminoacetophenone (A), Ch-4Bromoacetophenone (B)

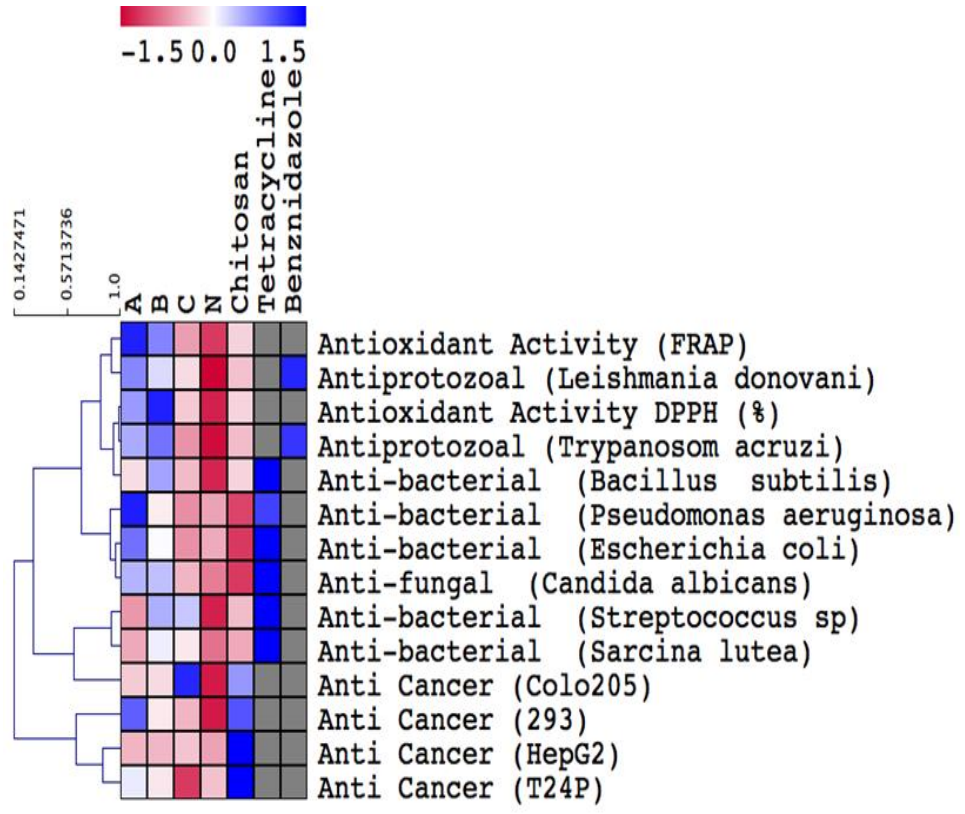

Tetracycline standard (antibacterial), Benznidazole standard (antiprotozoal)

\section{Biological activity}

The different biological activities of chitosan and its acetophenone Schiff base derivatives are represented in the heat map Figure 5. The activity of the new materials depend on the existence of new moiety such as amino and bromo groups which have biological activity [16]. The derivatives Ch-4Aminoacetophenone enone (A) and Ch-4Bromoacetophenone (B) showed higher antioxidant activity according to FRAP and DPPH methods. Similarly, compared to chitosan, Ch-4-Aminoacetophenone (A) and Ch-4-Bromoacetophenone (B) derivatives significantly possess higher anti-protozoal (Trypanosoma cruzi, Leishmania donovani), but this activity was lower than the antiprotozoal standard (Benznidazole). Antibacterial (Streptococcus sp., Bacillus subtilis and Sarcina lutea as an example for Grampositive bacteria and Pseudomonas aeruginosa and Escherichia coli as an example for Gram-negative bacteria) and antifungal activity (Candida albicans), activities were also increased by compounds Ch-4Aminoacetophenone (A) and Ch-4Bromoacetophenone (B). Regarding anti- cancer activities were recorded mainly for chitosan. The highest anti embryonic kidney adenocarcinoma (293) activity was recorded for compound Ch-4-Aminoacetophenone (A). The higher biological activity of aminoacetophenone derivative is due to its electron donating nature [10].

\section{Conclusion}

Chitosan was modified with Acetophenone derivatives through Schiff base reaction giving Ch-4-Aminoacetophenone and Ch-4Bromoacetophenone. The success of the reaction is confirmed by FT-IR with the disappearance of band related to $\mathrm{NH}_{2}$ and appearance of band related to $\mathrm{N}=\mathrm{C}$ bond. The thermal behavior of derivatives showing the less thermal stability of new modified materials comparing to the parent chitosan. The difference of crystallinity of chitosan and the modified materials is confirmed by X-ray diffraction. Also, SEM images showed the changes in morphology between chitosan and its derivatives. Biological activity of Chitosan and Schiff base derivatives were evaluated as antibacterial against Streptococcus sp., Bacillus subtilis and Sarcina lutea as an example for 
Gram-positive bacteria and Pseudomonas aeruginosa and Escherichia coli as an example for Gram-negative bacteria, Antifungal against Candida albicans, Antiprotozoal against Trypanosoma cruzi, Leishmania donovani, Antioxidant by DPPH and FRAP methods and anticancer activity against Colon carcinoma (Colo 205), hepatocellular carcinoma (Hep G2), urinary bladder carcinoma (T24P) and embryonic kidney adenocarcinoma (293). From the obtained results the derivatives showed a higher biological activity over unmodified chitosan except in case of anticancer activity in which the chitosan was superior.

\section{Disclosure statement}

No potential conflict of interest was reported by the authors.

\section{References}

[1] K.A.A. Pereira, L.R. Osório, M.P. Silva, K.S. Sousa, E.C.d. Silva Filho, Mater. Res., 2014, 17, 141-145.

[2] H.S. Mohamed, N. Soliman, D.A. Abdelrheem, A.A. Ramadan, A.H. Elghandour, S.A. Ahmed, Heliyon, 2019, 5, e01287.

[3] N. Soliman, H.S. Mohamed, S.A. Ahmed, F.H. Sayed, A.H. Elghandour, S.A. Ahmed, Environ. Technol. Innovat, 2019, 15, 100365.

[4] H. Abd El-gawad, A.M. Saleh, S. Al Jaouni, S. Selim, M.O. Hassan, M.A. Wadaan, A.M. Shuikan, H.S. Mohamed, W.N. Hozzein, Sci. Total Environ., 2019, 665, 690-697.

[5] M. Rinaudo, Prog. Polym. Sci., 2006, 31, 603632.
[6] N. Nwe, T. Furuike, H. Tamura, Isolation and characterization of chitin and chitosan from marine origin, Adv. Food Nutrit. Res., 2014, 72, 1-15.

[7] M.E. Mahmoud, M.T.A. Kana, A.A. Hendy, Int. J. Biol. Macromol., 2015, 81, 672-680.

[8] T.M. Tamer, M.A. Hassan, A.M. Omer, W.M. Baset, M.E. Hassan, M.E. El-Shafeey, M.S.M. Eldin, Process Biochem., 2016, 51, 17211730.

[9] L.R. Osório, I.S. Lima, H.M. Barreto, J.A. Osajima, E.C. da Silva Filho, Mater. Sci. Forum, 2016, 869, 869-873.

[10] E.A. Soliman, S.M. El-Kousy, H.M. AbdElbary, A.R. Abou-zeid, Am. J. Food Technol., 2013, 8, 17-30.

[11] M.W. Sabaa, A.M. Elzanaty, O.F. AbdelGawad, E.G. Arafa, Int. J. Biol. Macromol., 2018, 109, 1280-1291.

[12] S.A. Selim, M.H.A. Aziz, M.S. Mashait, M.F. Warrad, Afr. J. Pharm. Pharmacol., 2013, 7, 725-735.

[13] A. Mohamed, W. Sabaa, A. El-Ghandour, M. Abel-Aziz, O. Abdel-Gawad, J. Am. Sci., 2013, 9, 247-264.

[14] F.A. Tirkistani, Polym. Degrad. Stab., 1998, 60, 67-70.

[15] K.S. Sousa, E.C. Silva Filho, C. Airoldi, Carbohydr. Res., 2009, 344, 1716-1723.

[16] N.A. Mohamed, M.W. Sabaa, A.H. ElGhandour, M.M. Abdel-Aziz, O.F. AbdelGawad, Int. J. Biol. Macromol., 2013, 60, 156-164.

[17] B. Räz, M. Iten, Y. Grether-Bühler, R. Kaminsky, R. Brun, Acta tropica., 1997, 68, 139-147.

How to cite this manuscript: Olivia H. Raouf, Samy Selim, Hussein Mohamed, Omayma F. Abdel-Gawad, Ali M. Elzanaty, Sayed A. Ahmed, Synthesis, Characterization, and Biological Activity of Schiff Bases Based on Chitosan and Acetophenone Derivatives, Adv. J. Chem. A, 2020, 3(3), 274-282. 